\title{
La educación en la época de la esclavitud neoliberal: imagen para pensar la institucionalidad pedagógica latinoamericana*
}

Education in the era of neoliberal slavery: an image for thinking about Latin American pedagogical institutionality

A educação na época da escravidão neoliberal: imagem para pensar a institucionalidade pedagógica latino-americana

José Díaz Fernández ${ }^{* *}$

\section{Resumen}

En el presente artículo se ensaya un diagnóstico crítico de la situación vigente en educación, desde la conjunción de la filosofía neoliberal con la tradición filosófica política de la educación latinoamericana, con el propósito de establecer e instanciar la pregunta por el rol del profesor (concebido metafóricamente como curador del market) y el quehacer de la pedagogía de la liberación en la actualidad latinoamericana.

* DOI: http://dx.doi.org/10.15332/s0120-8462.2016.0115.11

* Licenciado, Magister y candidato a Doctor en Filosofía de la Universidad de Chile. Profesor de filosofía y lógica e investigador en filosofia latinoamericanaCorreo electrónico: josediaz@ug.uchile.cl 
La investigación en su contexto más amplio -en cuya base se encuentra la filosofía política de la educación nuestroamericana- se propone propiciar un diálogo participativo y reflexivo que sumerja la discusión actual en educación y política en una categoría como la esclavitud social y escolar, siempre con el imperativo de pensar desde y para Latinoamérica.

Palabras clave: filosofía nuestroamericana, pedagogía de la liberación, neoliberalismo, educación y política, curador del market.

\section{Abstract}

In this article a critical diagnostic of current situation in education will be assayed, from the conjunction of the neoliberal philosophy with political and philosophical education tradition of Latin America, with the aim of establishing and instantiate the question of the role of the teacher (conceived metaphorically as market curator) and the work of the liberation pedagogy in the Latin America present.

The research in its broadest context which is base on the political philosophy of education "nuestroamericana", it is proposed to begin a participatory and reflective dialogue to immerse the current discussion in education and politics in a category such as social and academic slavery, always with the imperative to think from and for Latin American.

Keywords: Philosophy “nuestroamericana”, liberation pedagogy, neoliberalism, education and politics, market curator.

\section{Resumo}

Neste artigo se ensaia um diagnostico crítico da situação atual na educação, desde a conjunção da filosofia neoliberal com a tradição política da educação latino-americana, com o propósito de estabelecer e instar a pergunta pelo papel do professor (concebido metaforicamente como curador do market) e as tarefas da pedagogia da libertação na atualidade latino-americana. 
A pesquisa em seu contexto mais amplo - em cuja base se encontra a filosofia política da educação nossoamericana- propõe-se propiciar um dialogo participativo e reflexivo que coloque a discussão atual em educação e política em uma categoria como a escravidão social e escolar, sempre com o imperativo de pensar desde e para Latino-américa.

Palavras-chave: Filosofia nossoamericana, pedagogia da libertação, neoliberalismo, educação e política, curador do market.

El inicio de la segunda década del siglo XXI nos dejó con las manos y las palabras atadas al comprender en profundidad la filosofía de Paulo Freire y el neoliberalismo reinante, quedando inmersos en la imposibilidad de hacer justicia a la educación. En la siguiente exposición ensayaré un diagnóstico de la situación actual en educación desde la conjunción de la filosofía neoliberal con la tradición filosófica política de la educación latinoamericana, para luego establecer e instanciar la pregunta por el rol del profesor y el quehacer de la pedagogía de la liberación en la actualidad. Para ello comenzaré con la exposición de una metáfora y caracterización del rol del profesor que he denominado el educador como curador del market, que retomaré a la finalización de esta exposición con el fin de referirme a la actualidad de la práctica "liberadora".

Desde los aportes de la filosofía política de la educación nuestroamericana, el trayecto de este estudio -presuntuoso e inacabado- está destinado, por una parte, a ensayar la condición esclavista de la educación y la sociedad actual, y por otra, a propiciar un diálogo que sumerja la discusión actual en educación y política en categorías como esclavitud social y escolar. Lo anterior, se plantea desde el imperativo de pensar desde y para Latinoamérica (considerando, tanto autores y obras latinoamericanas como otras tradiciones), y para ella, para una tierra esclavizada y dominada por el robo de sí, que muy bien puede ser toda la Tierra, pues, en continuidad a lo expresado por Enrique Dussel (1998), ya no podemos pensar una filosofía para Latinoamérica sino que una para la exclusión de la globalización mundial. 


\section{El educador como curador del market}

El siglo XIX, descrito como el periodo de implantación de la Modernidad/ Colonialidad en la generación de los jóvenes estados-nacionales fratricidas, posiciona la discursividad educacional desde la imagen del herrero, donde tanto Don Andrés Bello (Ruiz, 2010) como Juan Bautista Alberdi (Alberdi, 1978) son un ejemplo claro de ello. Al entrar el siglo XX, la discursividad que condujo la figura del educador como un ejemplo de moralidad, liberador o mesías de lo social, esto es, un formador de hombres y mujeres civilizados, libres o emancipados -donde la educación cívica o ética cívica es una de sus principales manifestaciones-, migro hacia la construcción de una subjetividad en crisis, una que se debió debatir entre la aceptación del libre mercado con su método de producción capitalista -en la figura de John Stuart Millcon el imperativo de expedir en grados creciente la libertad individual, que no tardó en producir un demonio bicéfalo, cuya magnificencia se basa en que una de ellas nunca ha de devorar la más débil, consciente de su propia destrucción, el sistema educacional tiene que producir la esperanza viva de la democracia como alimento para el capitalismo globalizado antidemocrático-dictatorial.

La imagen del rol de la educación, ya en las últimas décadas del siglo XX, se estructuró con base a la construcción de un profesor como la figura de un administrador y productor de la mercancía social, cuya finalidad es capitalizar a los educandos como meros instrumentos de mercado, es decir, objetualizando el ser humano -en su ámbito pedagógico- en mercancía (Becker, 1975; Schultz, 1968); cuestión que niega toda subjetividad en capital humano, o quizás, reformula el proceso de subjetivación desde el ya caduco proyecto Moderno/Colonial iluminista hacia su lado oculto como capitalismo salvaje: pero todas estas cuestiones ya nos son obvias (Foucault, 2007). Es importante destacar aquí que estas mudanzas de roles no se presentan como un simple cambio de vestidura, más bien, todo lo contrario, marcaron la historia desde el despojo y la exposición a la muerte que la historia latinoamericana atestigua en sus anchas.

Como bien ya comprendimos, la conversión de la educación hacia el capital humano traerá consigo una praxis de control altamente especializada sobre los educandos, pero principalmente sobre el educador, cuya praxis terminará por constituir un clima de estabilidad emocional y política, desarrollándose en la conciliación -en el mejor de los casos- de irrupciones en un diálogo inmovilizante, en resumen en la antidiálogicidad de Paulo Freire (2012), pues preocupado del complimiento de 
metas y objetivos pauteados el mantenimiento del silencio y el orden en salas de clases diversas, irruptivos y multiculturales se vuelve urgente (Torres, 2007). Esta máquina, que se declara abierta al diálogo, la democracia y la libertad; las cuales no son negadas, ellas tienen un lugar primario en sus declaraciones de principios, más bien son ocluidas en la ausencia de tiempo para su tratamiento crítico efectivo en el aula. Así como también, las comunidades educativas de conversación y reflexión promovidas por las agencias internaciones son recogidas con énfasis por los centros educativos de base quedando ocluidas en la urgencia de capacitación, en la última reformulación de la neurociencia y el neuroaprendizaje, promovida desde los mismos centros internacionales. El moderno sistema neoliberal borra con el codo lo que escribe con la mano.

La consecución de este aparato de control neoliberal es posible ser interpretada como un llevar a la práctica educativa la exigencia de la generación de un producto individual -esto es singular a todo otro producto- y a su vez homogéneo (idéntico a todo otro) como sedimento y requerimiento de la idea de nación moderna en vías de modernización, cuestión que Dussel nos transparentará desde la falacia desarrollista (Dussel, 2007; Hinkelammert, 1970). La compleja dinámica de esta ilusión, que es recogida ampliamente en la discusión Modernidad/Colonialidad (Castro-Gómez y Grosfoguel, 2007), es desde donde me permito proyectar aquel funcionamiento, donde el avance de la sociedad neoliberal que exige y requiere la construcción de una subjetividad abierta a la irrupción (de nuevas mercancías) y al conflicto en sí misma (como un estado de constante carencia), pero contenida en sí misma, es decir, en los espacios ya abiertos (Adorno, 2001). Con base a estos elementos es posible señalar que la vestidura o rol de la educación se constituye en nuestra actualidad a imagen de un conservador (o curador) de la totalidad (del estado neoliberal universalizado, es decir, globalizado), cercenando la capacidad de los educandos y educadores para contribuir, producir o generar espacios de escucha y promoción de saberes y prácticas no institucionalizadas, diversas o alternativas a la promovida por la educación institucional u oficial.

Es así como la educación se revela como una sofisticada institución que expresa, expone y administra, en resumen, exhibe el saber, con el único fin que los administradores de este logren distribuirlo en las mejores condiciones posibles a un público cada vez más "empoderado" y "sofisticado". No obstante, esta no es una tarea simple ¡todo lo contrario! es una tarea compleja, la cual debe ser realizada lenta y progresivamente 
con la delicadeza de un curador de arte moderno, cuidador del fondo y los marcos del saber, que obrará evitando a toda costa la corrosión (la autodestrucción de la obra por la poca virtud de sus materiales), el ataque de las termitas (la destrucción de la estructura de la obra por la exterioridad animal), los grafitis (que nubla la imagen como una expresión de arte alternativo al oficial), o de un robo (que se apropia de un bien público transformándolo en privado). Y es precisamente en los marcos del saber donde me detendré con los insumos de la filosofía política de la educación latinoamericana.

\section{La filosofía política de la educación latinoamericana}

El filósofo brasileño Paulo Freire es reconocido por contribuir con un avance significativo al análisis de las relaciones intersubjetivas. La influencia de su Pedagogía del oprimido (2007) ha sido un llamado de atención a toda práctica educativa presente.

Por su parte, Iván Illich en su análisis de La sociedad desescolarizada (2006b) adelantó una crítica a la institucionalidad pedagógica que nos sorprende con una advertencia a todas las prácticas educativas, también las "liberadoras". Este pensador, con quien Paulo Freire realizó durante los años sesenta y setenta un fructífero diálogo (Freire, 2010; Dussel, 1977), nos enrostra la crudeza del pensamiento único que toda forma de educación traería consigo. Y aquí debemos ser enfáticos en el carácter de totalidad que los mitos de la vieja y gorda vaca sagrada nos ha introyectado, y nosotros en el mejor de casos reproduciríamos con algún índice de criticidad: el mito de que los valores institucionalizados (las construcciones de saberes y poderes educaciones) y del saber dependiente de una autoridad (como por ejemplo el profesor liberador) constituyen en los estudiantes la imagen que el saber es un producto que se puede alcanzar (y no construir), y por ende, que es dispensado por un único distribuidor, como una única forma posible de conocimiento y desarrollo personal.

Enrique Dussel (aunque posterior a esta discusión) en su desconstrucción de la ontología tradicional logró representar la filosofía de la liberación como una crítica a la ontología de la dominación, que se transparenta como una práctica educativa enmarcada desde la figura del Anti-Emilio (Dussel, 1977), donde el exterminio cultural, bajo la idea del analfabetismo y la huerfanidad, cimienta las bases para la imposición de una cultura de la dominación, que disocia totalmente los contenidos propios, comunitarios y familiares de la practica educativa. 
Al pensar estos filósofos de forma conjunta, como un proceso de interconcientización, es factible concluir que estos develaron diversos ámbitos de las relaciones antidemocráticas y colonizadoras que la praxis pedagógica ha constituido en Nuestra América. Y con ello, podemos señalar que no será ni la representación en la figura de la episteme moderna bajo el establecimiento del "profesor" como una autoridad dispensadora y reguladora, ni la participación plena y horizontal en un proceso co-constituyente educador/educando, las capaces de comprender la dominación en la educación y reformular el espacio político que ella significa. La primera porque contribuye a perpetuar la lógica/pedagogía de la dominación de un sujeto sobre el objeto (naturaleza y sujetos otros), de la cual las escuelas efectivas, eficientes o de excelencia son un fiel reflejo (Carrasco, 2013); y la segunda por negar la relación crítica del educador al educando (Dussel, 1977), dejando al arbitrio de los intereses particulares una responsabilidad comunitaria. Como lo es la de proveer de las mejores herramientas para la producción y la reproducción de la vida de la forma más digna y sustentable que la historia de la vida humana ha desarrollado (Puiggrós, 2005).

La modernidad impedida de promover la diferencia -que Illich (2006a) y Dussel (2007) consideran la única alternativa posible al estado de dominación actual- y la singularidad anula la posibilidad de nutrir vías alternativas de desarrollo humano. La educación, como ya comprendemos, se ha transformado en una praxis e institución conservadora (del neoliberalismo actual). Donde todo saber que no construya el sentido como un ser uniforme y dispuesto al consumo no recoge la validez y legitimidad que el control universal del mundo globalizado requiere; negando con ello la posibilidad de superación del sentido actual del mundo, es decir, transformando toda alternativa en "pasado", en lo "ya sido", en exclusión como ancestral, folclórico o testimonial negándola como posibilidad futura (Hinkelammert, 1970).

La bancarización de la educación -idea planteada por Freire- nos sumerge curiosamente en el seno de la modernidad y el límite de nuestra actualidad, pues no es sino la economía como ciencia (Roll, 1994) el mayor logro de la Modernidad/Colonialidad, puesto que es a través de esta praxis "científica" que toda una episteme esconde su accionar. En una regulación epistémica y política (Saber/Poder) falsamente universal y necesaria, se establece una jerarquización de los seres según el grado de similitud a un único modelo válido de existencia: la neoliberal, fenómeno encargado de implantar un saber y un hacer que buscan construir e instanciar un sujeto absoluto epistémico. 
El quehacer democrático en educación -contra el absolutismo de un discurso unívoco como absoluto epistémico de enunciación- es la primera barrera para el silenciamiento de lugar de escucha (locus audentiae) y la dominación, que los pensadores de la filosofía política de la educación latinoamericana como Freire, Illich y Dussel se han empeñado en edificar. Un rasgo característico de esta "tradición"1, ante la negación epistémica del otro (del educando), es la valoración de la comunidad como el sujeto y objeto de reflexión; cuestión que lleva implicada una distancia menor entre la filosofía/ teoría/educador (sujeto reflexivo) y la comunidad/praxis/educados (objeto y lugar de reflexión), relación que tendería (próxima) a disolver esta relación de jerarquía epistémica no en la disolución del educador en la comunidad, sino en la integración, por una parte, de la comunidad en el educador (en su propia educación) y por otra, del educador en la comunidad, como un sujeto político de la misma.

Las instancias anteriormente señaladas atestiguan -hacia el ámbito institucionaluna crítica al afán imitativo con que se ha pensado e implantado la educación $n^{2}$ en Latinoamérica, las cuales imponiendo una posición de inferioridad (denominada subdesarrollo, tercer mundo, países emergentes, en vías de desarrollo entre algunos de los tópicos) han ordenado planes y programa de desarrollo con base a metas de crecimiento neoliberal, de concentración y acumulación de capitales por las metrópolis extranjeras al continente: desde Reino de España -y con ello toda Europahasta los Estados Unidos de América. El absolutismo del discurso univoco, ya sea del capitalismo modernizador de la década de los setenta o del actual capitalismo neoliberal, comparten una práctica de dominación que ha manifestado la estructura de la colonialidad latinoamericana: el ensordecimiento del educando, una práctica de colonialidad que es posible rastrear hasta el presente, iniciando con un proceso de alfabetización y exterminio de la diversidad lingüística, de adoctrinamiento pedagógico teológico, de modernización, mutilación de la creatividad y la alternativa al modelo único civilizador. Prácticas con el máximo común denominador de fortalecer la comprensión univoca de las capacidades del ser humano.

1 El término tradición debe ser comprendido en su comprensión dialógica, es decir, un grupo medianamente delimitado (por intereses comunes y una cultura común) que comparte un acuerdo fundante provisional. Esta comprensión es deudora de conversaciones sostenidas con el filósofo de la liberación Carlos Cullens.

2 En su acepción institucional. 
El segundo ámbito que es importante destacar en esta exposición de la filosofía política de la educación nuestroamericana es ético, en el cual recogeré al filósofo Augusto Salazar Bondy (1975) -en la recepción de las ideas esbozadas por Illich- es la justificación ética del quehacer educativo que ejerce un sujeto sobre otro. Las pedagogías de los oprimidos, como ya ha sido mencionado, pregonan un vínculo más estrecho entre la teoría y la praxis (entre educadores y educandos), empero aquello no subsume la una en la otra, sino que expresa la distancia infranqueable entre los "componentes" de la relación educativa, así como entre la teoría pedagógica y la praxis de liberación pedagógica, propiciando la emergencia del sujeto en cuanto fundamento de las relaciones pedagógicas, y no como objeto de las políticas educacionales (de dominación o liberación).

La distancia infranqueable entre los componentes de la relación pedagógica (o juicio educativo) es condición de posibilidad y reflejo de un educador que no subsume al educando hacia su propio juego de reglas de producción y reproducción de la vida (capitalismo, neoliberalismo, socialismo real, socialismos del siglo XXI, etc.). Es decir, un distanciamiento crítico, que a los ojos de Dussel, es condición de posibilidad y reflejo de la proximidad que requiere para sí una comunidad dialógica y no una mera "masa" (Dussel, 1977). El peligro de no considerar este elemento, la distancia infranqueable entre el educador y el educando, debe ser pensado desde dos ámbitos: 1) desde la asimilación e identificación total del educando con el educador que no deja espacio para la exploración de alternativas a lo impuesto por el educador, subsumiéndolo en su propio juego reglas, 2) desde la total exclusión del educador con el educando. Lo cual, en el mejor de los casos, instituye la diferencia como indiferencia, la ausencia de responsabilidad crítica pedagogía, y en el peor de ellos, instituye la diferencia como enemistad: como un sujeto que es necesario eliminar, convirtiéndolo en un huérfano cultural. Si bien, lo anterior no se encuentra desarrollado bajo términos idénticos en las pedagógicas analizadas, estos se encuentran presentes en la "diálogicidad" -entendida como "concientizaçâo"- en Freire, "educación de todos por parte de todos" en Illich, y en la compleja "palabra reveladora de la voz del otro" de Dussel, constituyéndose en un rasgo característico de la filosofía política de la educación nuestroamericana desde 1970 hasta la actualidad (Díaz, 2014).

La crisis de la racionalidad educativa modernizadora da cuenta del lugar que ocupa el sujeto y el objeto en la pedagogía, crisis que no implica ni la muerte del sujeto ni la incognocibilidad del objeto, sino la intercambiabilidad constante del sujeto y el objeto 
en la relación o juicio educativo. Lo anterior contribuye a la justificación (fundante) normativa (acuerdo) del quehacer de un sujeto (educador) sobre otro (educando), la cual se estructura mostrando idénticos a ambos sujetos de la relación educativa, en la identidad ética y epistémica. Así, entre el educando (otrora objeto de la educación) y el educador (otrora el sujeto educador) se disuelve el cuestionamiento por la validez y legitimidad de uno por sobre el otro. Es por ello que el acento en estas pedagógicas se encuentra en la labor co-constituyente o co-fundadora de los participantes de la relación educativa (juicio pedagógico); y es precisamente aquí donde la concientizaçâo y la "liberación", como procesos inacabados, y principalmente inacabables suspenden la cosificación del objeto (educando) y el saber/poder del sujeto (educador). Y en tanto procesos inacabados e inacabables incorporan un tercer elemento: la política, a lo cual volveré más adelante.

La reflexión contenida en el grupo Modernidad/Colonialidad, en su traducción por Liberación/Dominación ${ }^{3}$, adquiere pleno sentido cuando es considerado un aporte a las pedagogías de los oprimidos y a la filosofía política de la educación nuestroamericana, despertando la educación del sueño del absoluto bien. Donde su lugar de enunciación ocupa el puesto del Leviatán contemporáneo, arrojándose el derecho a construir a todo ser en "persona", y más aún en "mejores personas", con la metodología más sofisticada y adecuada para producir "un bien" a la sociedad, cuyo gesto crítico podemos rastrear en la discusión latinoamericana en Illich, en particular en sus obras Alternativas (2006a) y La sociedad desescolarizada (2006b).

El traspaso de la responsabilidad colectiva-comunitaria de la educación hacia los intereses privados mercantiles, y un saber totalizante encapsula el aprendizaje y el conocimiento en una única (totalizante) comprensión de las capacidades del ser humano como "capital humano" y el saber como "bien de mercado", son la expresión glorificada y universalizada de la educación bancaria en su máxima significación. La elección autoregulativa "racional" de las familias en el plexo de posibilidades -a las que puede tener acceso según sus recursos disponibles en el mercado- reproduce nuevamente el mito de la modernidad, pues un mercado que obra maximizando la oferta (estimulando la incorporación de operadores educacional) y reduciendo la capacidad de demanda (produce la educación como un "bien escaso y privilegiado"

3 Traduzco Modernidad/Colonialidad por Liberación/Dominación con el fin de hacer notar la imposibilidad en entender la educación si no es bajo un binomio insuperable de liberación y dominación, que el quehacer educativo conllevaria. 
mediante su costo), funciona bajo un supuesto falso de plena autonomía, igualdad y libertad contractual de los seres humanos.

La modernidad repliega su mito en la falsa competencia perfecta/universal, racional/ autónoma y libre de contratar (elegir la mejor educación posible) sin ninguna barrera particular o irracional (de clase, genero, raza o razón social), cuestión empíricamente falsa. La colonialidad del poder, aquella colonia que continuó viviendo en la República con que nos inspira José Martí (2005), designa suficientemente bien a quienes serán los portadores de la total capacidad racional y universal de elegir con plena libertad los fines entre el universal total de los "bienes del mercado". La estandarización del saber producido por la medición masiva en la educación -pruebas estandarizadas- es una de las manifestaciones de la colonialidad del saber, donde el impedimento liberal y trascendental de determinar los límites del saber, sus posibilidades de expansión y creación - "Contenidos Mínimos Obligatorios" y "Objetivos Transversales"-, amputan y cercenan las posibilidades del saber desde la promoción, rendición y financiamiento (accountability) de un tipo único de saber que puede ser medible, comparable, testeable y por último auditable (Carrasco, 2013).

Las razones "obvias" -enfatizo las comillas- de la ausencia de los educandos de la relación pedagógica, como su corta edad y en ello inmadurez, se revisten en términos políticos cuando la inserción de contenidos pedagógicos (curriculares y metodológicos) se realiza en pos de la realización política y económica de intereses ajenos -bajo la banderas del progreso universal y liberal- en desmedro tanto de las comunidades como de una Latinoamérica empobrecida e impedida de crear o reconocer nuevas formas de producción y reproducción de la vida, lo cual estructura el componente fundamental de la dominación (ya no solo latinoamericana sino globalizada): el impedimento sistemático e institucional de búsqueda de nuevas y mejores formas de realización del ser de lo humano ${ }^{4}$.

Una de las constataciones de esta negatividad la encontramos en que el "bien", al ser pensado desde esta lógica, transfiere su justificación desde el poder y la autoridad

4 Un sentido similar, aunque más cercado temporalmente a los procesos cívicomilitares posterior a la década de los setenta, puede ser comprendido a través de Grosfoguel (2003), quien presenta un análisis del funcionamiento de las Ilamadas "vitrinas desarrollistas", como el principal articulador de los Estados-naci n cívico-militares en su tarea por posicionar culturalmente la dominación neoliberal. Las cuales presentan las nuevas mercancías como objetos del deseo, gloria y bienestar de la nueva sociedad, unificando el gusto y el deseo. 
como poder-ser (como posibilidad de creación y transformación: potentia) hacia la vocación de un "ser llamado" para cumplir y hacer cumplir la misión del progreso humano en el desarrollo neoliberal (Dussel, 2006). El momento ético de evaluación y proyección de la filosofía política de la educación nuestroamericana da cuenta de la necesaria articulación con lo político. El reconocimiento de lo propio o de lo latinoamericano en categorías de valor (legitimidad) y verdad (validez) atisban la manifestación política del reconocimiento de lo "propio" ante una cultura extranjera, que caracterizada bajo la colonización, fundamenta la urgencia de la creación como valor político por excelencia. Es por ello que la educación desborda en la política, cuando es desde ella que es puesto de manifiesto su finalidad constituyente o continuadora.

\section{La actualidad de la libertad y el derecho}

El filosofó Friedrich Hayek, que en su más afamada publicación Camino de servidumbre (2008), expone su filosofía como el resultado necesario del libre progreso de la humanidad, donde la vulgaridad de todo pasado preburgués sitúa a este pensador en el hemiciclo de un Leviatán, capaz de juzgar todo pasado concreto y todo futuro posible desde la extraordinariedad de la única comprensión verdadera, natural o universal del mundo. La nueva forma de la esclavitud pedagógica nace como la absoluta penitencia a un fundamento de autoregulación mercantil, erigido con validez universal, absoluta e incomprensible. $Y$ es ante este fundamento que el ser humano queda reducido a una nada que se debe someter en entera sumisión a sus reglas -que, por cierto, desconoce y nunca lograra conocer- (Hayek, 2008).

En este punto, el pensador austriaco logra dar con una descripción profunda de la libertad contemporánea y la labor que debe cumplir la educación, el despliegue de la pura voluntad de poder y de la competencia, dentro de marcos ya establecidos, que por definición, el ser del humano es incapaz de comprender. La actualidad profanada de la libertad, raptada en la elección como única libertad posible (cuyo última elección es la muerte), se desvanece en una disposición instrumental de la "razón de elección" entre lo ya dispuesto para la reproducción de la vida. La libertad llegará a la sociedad actual como una libertad negada, esclava de su fundamento ontológico, subordinada en hecho y derecho a la regulación incomprensible de la economía política neoliberal, coronando al soberano del mercado (market). Donde los seres más libres serán aquellos que hayan de interiorizar con pasión y pleitesía la regulación de su fundamento invisible e irracionalizable. 
La identificación de un principio económico con una necesidad política convierte a Hayek, con una visión más amplia en términos temporales de la historia "universal" y de la economía capitalista, en un virtuoso traductor de Adam Smith. La libertad natural que otrora sonaba como un "estado de guerra de todos contra todos" es subsanada por el ejercicio pleno y libre del soberano, llegando a ser sublimada por la competencia mercantil regulada por el ejercicio pleno y libre de la mano invisible: "no niega, antes bien, afirma que, si la competencia ha de actuar con ventaja, requiere una estructura legal cuidadosamente pensada" (Hayek, 2008, p. 125). En otras palabras, el libre desempeño de las capacidades humanas requiere la regulación activa de la desregulación natural. Esta contrariedad no hace más que edificar en filosofía la finalidad de esta comprensión del mundo: el libre tránsito de las mercancías.

La perversión de la regulación de las mercancías no es injusta contra una voluntad particular, sino que es un daño absoluto. Esta negación se ejerce contra fundamento del mundo, en otras palabras, es una negación de la ontología soberana a la cual el ser humano debe someterse en absoluta pleitesía. El principio económico de no regulación de las mercancías adquiere un carácter necesario y no inteligible, naciendo en forma de negación trascendental a priori para la comprensión racional del ser humano. La nueva forma de la esclavitud (la neoesclavitud) nace como la absoluta penitencia a un fundamento de autoregulación mercantil, erigido con validez universal, absoluta e incomprensible. En este punto, el pensador austriaco logra dar con una descripción profunda de la libertad contemporánea, es el despliegue de la pura voluntad de poder y de competencia. El principio ontológico de la imposibilidad radical del ser humano es el fundamento para el pleno control, dominio y promoción de esclavitud en la libertad.

En la filosofía de Hayek esta comprensión es conducida hacia al extremismo, reconstruyendo la democracia y la justicia en servició a este principio: "el precio de la democracia es que las posibilidades de un control explícito se hallan restringidas a los campos en que existe verdadero acuerdo y que en algunos campos las cosas tienen que abandonarse a su suerte" (Hayek, 2008, pp. 157-158). Y aquí no es complejo comprender que el campo de funcionamiento de la democracia se enmarca en el ámbito fundamental del mercado autorregulado por los intereses particulares, en el despliegue de la voluntad de poder y competencia, pues todo ámbito ajeno a este es injusto por naturaleza (va contra el fundamento ontológico del mundo); así como exento de acuerdo. La autonomía queda así negada desde el a priori ontológico de la 
economía política, pues no se trata sino de un proceso promovido y protegido de no interferencia contra el progreso totalidad y soberano de la "civilización”.

La transformación de la libertad económica en libertad política transfiere la naturalización de un principio técnico de regulación de las mercancías en fundamento de la constitución del ser de lo humano. Y es en este proceso que la legitimidad de un particular Estado de Derecho (Rule of Law) se naturaliza en un control universal de un mundo concreto. Así, podemos señalar que la democracia, la justicia y la libertad actual garantizan solamente la certidumbre y la servidumbre de cómo será usada la autoridad en toda circunstancia que pretenda una forma de vida contraria al fundamento neoliberal del mundo: anunciando el cese de la autonomía y la libertad por el reinado de la esclavitud.

La naturalización del principio de libre mercado (la mano invisible) concluirá en la edificación del muro que divide el ser del no-ser de la civilización. Es la libertad de mercado la que constituye la categoría fundamental del sentido actual del mundo, la cual, por una parte, desarrolla la justicia como un caudaloso progreso de relaciones individuales egoístas; y por otra parte, la injusticia como todo impedimento u obstaculización del movimiento uniforme del mercado. ;Caen las cadenas de la esclavitud para transformarse en las líneas de una frontera absoluta!

\section{Consideraciones finales}

El rol de la educación institucional se revela como una sofisticada institución que expresa, expone y administra, en resumen, exhibe el saber, con el único fin que los administradores de este logren distribuirlo en las mejores condiciones posibles. Es este sentido, la homogenización de las pruebas estandarizadas y la promoción de grados de ser (seres básicos, medios o superiores) son reflejos de una lógica de control pedagógico articulado desde una epistemología-política que sitúa muy bien los marcos del saber. Los horarios fijos de desarrollo pedagógico destinados a ámbitos de saberes específicos -materias con sus jerarquías internas reguladas por su distribución horaria- dividen, separan y aíslan la realidad de tal manera que esta pueda ser reflejada en indicadores únicamente cuantificables, es decir clasifican el saber y el ser.

Donde la estandarización de la regulación del saber (la validez epistemológica estandarizada) tienen como condición de posibilidad un saber ya homogenizado (un 
curriculum nacional por ejemplo); por ello es posible señalar que la unificación y articulación del objeto del conocimiento (el saber estandarizado) es el resultado de una elección subjetiva, en conformidad con el modo univoco de comprensión de lo real. La práctica de control pedagógica tiene su consecución final en disponer el mundo como un market; divide, separa y organiza las mercancías según el índice de ganancia -la principal categoría que impuso el sujeto absoluto contemporáneo sobre el mundo-, presentándonos la "buena" educación y el saber "legitimo" como el ejercicio de elección sofisticado y eficiente dentro del plexo total disponible de las mercancías (el objeto último de dominación es el mundo, nombrado por el Leviatán como mercancía).

Aquí es pertinente volver sobre la imagen de la educación bancaria, la que recobra una vigencia aún mayor. El velo de falsa neutralidad (la publicidad) con que son vestidos los objetivos procedimentales (o las competencias) no alcanzan a disolver su engaño, puesto que aquellos no logran liquidar su constitución material (saberes y no meros procedimientos).

El quehacer democrático contra el absolutismo de un discurso unívoco, como absoluto epistémico de enunciación privilegiada, la podemos catalogar como una de las primeras barreras para el silenciamiento de lugar de escucha (locus audentiae) y la dominación, que la negación epistémica del otro (del educando) entraña y la falsa universalidad de la modernización reproduce. El absolutismo del discurso univoco, ya sea del capitalismo modernizador de la década de los sesenta y setenta o del actual capitalismo neoliberal, con todas sus distancias y similitudes (Grosfoguel, 2003), es una clara práctica de dominación que ha manifestado la estructura de la Modernidad/ Colonialidad latinoamericana (Restrepo y Rojas, 2010). En este sentido, el ensordecimiento del educando es una práctica de colonialidad que se encuentra presente en las diferentes fases de la dinámica política-epistémica latinoamericana. El saber totalizante que encapsula el aprendizaje y el conocimiento en una única (totalizante) comprensión de las capacidades del ser humano como "capital humano" y el saber cómo "bien de mercado", son la expresión glorificada y universalizada de la educación bancaria en su máxima significación.

Es por ello la urgencia de la afirmación de la diversidad de saberes como posibilidades validas de comprensión del mundo, pues aquí se puede encontrar una de las principales armas contra la concepción moderna/modernizadora del saber y la educación, la cual considera la escuela como el único instrumento capaz de dotar a los hombres 
y mujeres de las herramientas para desempeñarse cabalmente en el mundo contemporáneo. Lo anterior representa el fundamento ontológico y epistémico con el cual la educación inicia su camino hacia la dominación de las aspiraciones del ser humano que no solo actúa sobre su realización, usando la terminología aristotélica (sobre los actos de los hombres), sino que actúa, preferentemente, sobre sus potencialidades, es decir, sobre la capacidad de representarse alternativas a lo ya dado (el único y mejor de los mundos posibles). Será este proceso el que conlleva la confusión de lo dado (la realidad) con la única posibilidad de ser (futuro): el poder-ser con el ser, que pone el presente como único horizonte de sentido (o significación), o en otras palabras, el neoliberalismo como el mejor y único mundo posible, y todo mundo alternativo como un mundo imposible, esto es, autocontradictorio. Y es contra aquello que la educación actual tiene el deber de revelarse. La autonomía dialógica, y el espacio que aquello significa en la educación, queda negada desde el a priori ontológico de la economía política -como ya fue señalado- en una esclavitud pedagógica que cercena todo proceso de aprendizaje que pueda formularse fuera del campo de la economía política neoliberal, ya sea desde el andamiaje de las producciones y los estándares de realización del conocimiento o desde su oclusión y reconocimiento en la ausencia de tiempo para su realización.

Por ello, la irrupción en el único espacio educativo, es decir, el momento donde el vaciamiento de la regulación educativa da espacio a una reestructuración y replanteo de los códigos de conducta y de proyecciones. Donde el reconocimiento de la diversidad se torna necesario para conseguir fines individuales, incapaces de ser alcanzados sin una coordinación comunitaria. Lo cual reclama de forma obligatoria la intromisión de la diversidad de fines en el proyecto individual "egoísta", y en ello, el descubrimiento de los límites de la proyección egoísta. Ahora bien, es labor del educador introducción la coordinación estructurada como proyecto de realización de los saberes, esto quiere decir, que no es el solo reconocimiento de la experiencia diversa o irruptivos sino su promoción y fundamentación como nuevo vinculo pedagógico de aprendizaje.

Las distinciones curriculares y categorías del saber científico (válido y legítimo) en contra de saberes marginales y emancipadores son uno de los tantos atentados contra la legitimidad democrática en la educación, y la posibilidad de irrupción, donde estos obran estableciendo un canon de saberes válidos (validez/verdad) y legítimos (política/ética) para su aplicación y manipulación sobre el mundo. Es por 
ello que la diversidad y complejidad de saberes y prácticas que subyacen a la falsa universalidad de la modernización neoliberal atrofia y mutila la praxis educacional: sesgándola y ensordeciéndola a los educando y sus comunidades, a sus propias determinaciones, y transformando al educador en un actor igualmente conservador e incapaz de contribuir, producir o generar espacios de escucha y promoción de saberes y prácticas no institucionalizadas, diversas o alternativas a la promovida por la educación institucional u oficial. En definitiva, podemos señalar que la constitución de una educación latinoamericana solo existirá si la educación en nuestras escuelas, y los profesores en ellas, son capaces de mirar a su propia realidad y lograr comprender que el mundo latinoamericano es uno que exige con urgencia avanzar hacia nuevos espacios democráticos, los que no pueden ser establecidos sin antes no haber comprendido el compañerismo y la diálogicidad critica liberadora como uno de sus pilares fundamentales.

Lo fundamental y el componente diferenciador que determina la preferencia por las pedagogías de la liberación, por sobre otras pedagogías críticas, radica en que estas últimas no conciben un lenguaje de la posibilidad o de la transformación de la realidad, es decir, de la colonialidad. La labor del filósofo o educador en la pedagogía nuestroamericana es un quehacer crítico, esto es, obraría distinguiendo dentro de la cultura popular lo introyectado por la cultura de la dominación imperial, nacional y de masas -en los términos de esta discusión-, pero además, tiene como objetivo traducir y fundamentar la posibilidad de una existencia a otra, desde los oprimidos, excluidos (desde el conjunto heterogéneo de los dominados) y la pobreza, es decir, desde el pueblo: la comunidad.

La importancia actual de las pedagogías de los oprimidos o de la liberación no radica en ser replicadas como métodos pedagógicos en un contexto para el cual no fueron creadas (replicando el funcionamiento colonial de la racionalidad pedagógica), sino que adquiere su radicalidad en contribuir a desconstruir los fundamentos de la política pedagógica, desde experiencias nacidas de la revisión crítica de las circunstancias políticas, éticas y epistémicas en microespacios de realización de lo comunitario. Constituyéndose en requisitos insoslayables a la hora de evaluar la pertinencia y la posibilidad de toda educación; cuya totalidad tendería a reclamar la resignificación de la universidad de las relaciones epistémicas, éticas y políticas, es decir, educaciones, ya no en la marginalidad y la exclusión, como exterioridad, sino en una nueva totalidad política, ética y epistemológica. 


\section{Referencias}

Adorno, T. (2011). Minima moralia. Reflexiones desde la vida dañada. Chamorro, J. (Trad.). Madrid: Taurus.

Alberdi, J. (1978). Ideas para un curso de Filosofía Contemporánea. México D. F.: Ediciones Universidad Nacional Autónoma de México.

Becker, G. (1975). El capital humano. Un análisis teórico y empírico referido fundamentalmente a la educación. Cáseres, M., y Vergara, J. (Trad.). Madrid: Alianza.

Carrasco, A. (2013). Mecanismos performativos de la institucionalidad educativa en Chile: pasos hacia un nuevo sujeto cultural. Revista Observatorio Cultural, 15, 4-10.

Castro-Gómez, S., y Grosfoguel, R. (2207). Giro decolonial, Teoría Crítica y pensamiento heterárquico. En Castro-Gómez, S., y Grosfoguel, R. (Eds.). El giro decolonial: reflexiones para una diversidad epistémica más allá del capitalismo global (pp. 9-24). Bogotá: Siglo del Hombre Editores.

Díaz, J. (2014). Filosofía política de la educación nuestroamericana: filosofía de la educación entre la dominación y la liberación de Latinoamérica. Tesis para optar al grado de magíster en Filosofía. Santiago de Chile: Facultad de Filosofía y Humanidades, Universidad de Chile.

Dussel, E. (1977). Filosofía ética latinoamericana. De la erótica a la pedagógica de la liberación, 3. México D. F.: Edicol.

Dussel, E. (1998). Ética de la liberación en la edad de la globalización y de la exclusión. Madrid: Trotta.

Dussel, E. (2006). 20 tesis de política. México, D. F.: Siglo XXI.

Dussel, E. (2007). Materiales para una política de la liberación. México, D. F.: Plaza y Valdés. Foucault, M. (2007). Nacimiento de la biopolítica. Pons, H. (Trad.). México, D. F: FCE. Freire, P. (2007). Pedagogía del oprimido. Madrid: Siglo XXI.

Freire, P. (2010). Pedagogía de la esperanza: un reencuentro con la Pedagogía del oprimido. Buenos Aires: Siglo XXI.

Freire, P. (2012). Pedagogía de la indignación. Buenos Aires: Siglo XXI. 
Grosfoguel, R. (2003, enero-febrero). Cambios conceptuales desde la perspectiva del sistema mundo. Revista Nueva Sociedad, 183, 151-166.

Hardt, M., y Negri, A. (2000). Imperio. Sadier, E. (Trad.). Buenos Aires: Paidós.

Hayek, F. (2008). Camino de servidumbre. Huerta, J. (Trad.). Madrid: Unión Editorial.

Hinkelammert, F. (1970). El subdesarrollo latinoamericano. Buenos Aires: Paidós.

Horkheimer, M., y Adorno, T. (2007). Dialéctica de la Ilustración. Chamorro, J. (Trad.). Madrid: Akal.

Illich, I. (2006a). Alternativas. Mayans, E. (Trad.). México D. F.: FCE.

Illich, I. (2006b). La sociedad desescolarizada. Espinoza, G. (Trad.). México D. F.: FCE.

Martí, J. (2005). Nuestra América. Caracas: Fundación Biblioteca Ayacucho.

Puiggrós, A. (2005). De Simón Rodríguez a Paulo Freire: educación para la integración iberoamericana. Bogotá: Unidad Editorial, Convenio Andrés Bello.

Restrepo, E., y Rojas, A. (2010). Inflexión decolonial: fuentes, conceptos y cuestionamientos. Colombia: Editorial Universidad del Cauca.

Roll, E. (1994). Historia de las doctrinas económicas. Torner., F., y Cháves, O. (Trad.). México: FCE.

Ruiz, C. (2010). De la república al mercado. Ideas educacionales y política en Chile. Santiago: Lom.

Salazar, A. (1975). La educación del hombre nuevo: la reforma educativa peruana. Buenos Aires: Paidós.

Schultz, T. (1968). Valor económico de la educación. Tancredi, S. (Trad.). México, D. F.: Editorial Uteha.

Torres, J. (2007). Educación en los tiempos de neoliberalismo. Madrid: Morata.

Walsh, C. (2009). Interculturalidad crítica y pedagogía de-colonial: In-surgir, re-existir y re-vivir. UMSA, Revista. Entre palabras, 3-4, 129-156. 